\title{
Serum Interleukin-8 in Patients with Different Origin of Intra-Abdominal Infections in Perioperative Period
}

\author{
Artem Riga *, Valeriy Boyko and Yuriy Grirorov \\ Surgery N 1 department, Kharkiv National Medical University Kharkiv, 61022, Ukraine \\ * Correspondence: yaartyom888@gmail.com
}

Received: 30 June 2019; Accepted: 4 September 2019; Published: 8 September 2019

check for updates

\begin{abstract}
Intra-abdominal infections (IAI) are associated with high levels of pro-inflammatory serum IL-8 and poor outcomes, but data on IL-8 levels in various inflammatory reactions are contradictory. A better understanding of the diagnostic role of IL- 8 is important, since the clinical relevance remains unclear. Methods: That was a single-center observational longitudinal cross-sectional study included 56 patients with various origins of intra-abdominal infections: 24 patients with postoperative abscesses, 12 patients with primary intra-abdominal abscesses, and 20 patients with diffuse peritoneal collection. Perioperative serum concentrations of interleukin-8 IL-8 were investigated at the day before surgery, on the 2nd-3rd day, and on the 5th-7th day after surgery. The hypothesis suggested that there was a difference in serum IL-8 in patients with IAI of different origin in the perioperative period. Results: The study showed that the level of serum IL-8 in patients with intra-abdominal infections of different origins is lower in comparison with healthy individuals. Despite the fact that we did not detect any statistically significant differences in the level of IL-8 in serum in IAI of different origin in the perioperative period, its lowest index was observed in the patients with postoperative abscesses on the 5th-7th days after surgical intervention. The levels of serum IL- $8 \leq 49.71 \mathrm{pg} / \mathrm{mL}$ and $\leq 48.88 \mathrm{pg} / \mathrm{mL}$ may serve as diagnostic markers for primary and postoperative abscesses with significant sensitivity and specificity. Conclusions: Our results differ from previous studies that showed high serum IL-8. High-quality clinical trials are needed to better comprehend the role of inflammatory mediators in IAI with different origin.
\end{abstract}

Keywords: intra-abdominal infections; serum interleukin-8; perioperative period

\section{Introduction}

The immune system is an important regulator of the response to intra-abdominal infections (IAI). Moreover, even different surgical approaches, such as laparotomy and laparoscopy, in different ways influence the immune response and development of intra-abdominal sepsis that was shown in experimental models [1,2]. The immune system activates and instructs adaptive immune responses, regulates inflammation, and mediates immune homeostasis (the balance between opposing pro-inflammatory and anti-inflammatory processes) [3]. Interleukin-8 (IL-8) is a pro-inflammatory multifunctional cytokine with different physiological functions, and the role of IL-8 in IAI was still missing from the big picture [4]. It modulates local and systemic acute and chronic inflammatory reactions [5]. Some studies demonstrate correlation of the IL-8 level with sepsis and postoperative trauma [6,7]. Investigation of normal IL-8 in a healthy individuals' response after intravenous introduction of endotoxin showed a maximal peak after $2 \mathrm{~h}$ and duration of $12 \mathrm{~h}$ [8].

IL-8 has been studied as a biomarker for many clinical conditions and is currently used by various medical subspecialties, either for rapid diagnosis or as a predictor of prognosis. IL-8 was studied in various hematological and oncological diseases, urinary tract diseases, autoimmune diseases, and sepsis [9-14]. 
A unified consensus and understanding of the role of serum IL-8 as a valid biomarker for early diagnosis and/or a biomarker for the prognosis of the different diseases, especially local infectious processes, is still being studied. For example, Hikmet Kocak demonstrated that IL- 8 was not the best marker for early diagnosis of bladder cancer, but might serve as a predictor of prognosis [15]. There is still not enough data on the IL-8 as a diagnostic biomarker in patients with IAI, especially in postoperative intra-abdominal abscesses.

IAI are still regarded as an important cause of morbidity and mortality worldwide, despite antibiotics application $[16,17]$. These infections are caused by Gram-negative, aerobic, and anaerobic mandatory and often mixed bacterial flora [18]. Early diagnosis of the IAI is important to assess the severity and improve the prognosis of disease [19]. The factors influencing progression of IAI include advanced age, malnutrition, pre-existing diseases, use of immunosuppressants, prolonged peritonitis, virulence of the pathogenic microorganism, and actual immune response [20]. However, the clinical relevance of these findings is not clear. Many clinical conditions generally require expensive and time-consuming investigations for their diagnosis. There is therefore a general need for exploring noninvasive markers in clinical medicine.

Objective: investigation of pro-inflammatory IL-8 serum concentration in patients with different origin of IAI in the perioperative period.

Hypothesis: There is a difference in serum IL-8 in patients with intra-abdominal infection of different origin in the perioperative period.

\section{Methods}

This was a single-center observational longitudinal cross-sectional study. Clinical specimens were obtained from 56 patients with different IAI attended to at the Hospital of State Enterprise "Institute of General and Emergency Surgery named after V.T.Zaytsev' National Academy of Medical Science NAMS of Ukraine" in 2016-2018. This study was authorized by the Ethics Committee of the Kharkiv National Medical University (Report No 6 from 5 October 2016). Inclusion criteria: Patients with primary and secondary IAI. The distribution of patients with IAI was as follows: 24 patients with postoperative abscesses (POA), 12 patients with primary intra-abdominal abscesses (PIAA), and 20 patients with diffuse peritoneal collection (PC) due to IAI only. Exclusion criteria: Patients who did not present IAI and those who did not agreed to participate in this study. For immunological analysis, $5 \mathrm{~mL}$ blood was obtained - by vacuum sterile disposable tubes (Vacutainer) at the day before surgical intervention, on the 2nd-3rd day, and on the 5th-7th day after surgical intervention and from 31 healthy volunteers (Control group). Serum was centrifuged at $800 \mathrm{~g}$ for $10 \mathrm{~min}$ at $4{ }^{\circ} \mathrm{C}$ and was being stored at $-20^{\circ} \mathrm{C}$ for three month, as recommended by the manufacturer. Extracellular IL-8 in the serum was assessed with the VectorBEST test system (Kyiv, Ukraine) cytokines kit, according to manufacturer's instructions, in immune enzyme analyzer "LabLine-90" (Austria). Statistical analysis was performed with the MedCalc version 14.8-(C) 1993-2014 MedCalc Software bvba (Acacialaan 22 B-8400 Ostend, Belgium). Descriptive analysis: Kruskal-Wallis ANOVA test (KW), Kaplan-Meier survival analysis, and Receiver Operating Characteristic (ROC) curve analysis. The difference in distribution of the serum IL-8 among polymorphic variant groups $(n \geq 3)$ was compared by two-way Kruskal-Wallis ANOVA test $(\mathrm{KW})$ of variance with power calculation. The value was considered significant if the power was more than 0.8 . ROC curves were constructed by calculating the sensitivities (true positive rate) and specificities (false positive rate) of all assays at several cut-off points with calculating area under the curve (AUC). For all statistical methods, $p<0.05$ was considered statistically significant.

\section{Results}

Among 56 patients with IAI of different origin engaged from the hospital with the average age 56 years old (ranging from 19 to 83 years), 26 were men. The common comorbidities were systemic hypertension and diabetes mellitus type 2 (Table 1$)$. About half (26/56) reported previous recent surgery 
due to IAI. The similar amount (26/56) of the patients underwent surgery using minimally invasive technologies. All patients took antibacterial therapy, according to hospital local protocol.

Table 1. Demographic and clinical variables of patients with different origin of intra-abdominal infections (IAI).

\begin{tabular}{|c|c|c|c|c|}
\hline Data & $\begin{array}{c}\text { POA } \\
n=24\end{array}$ & $\begin{array}{c}\text { PIAA } \\
n=12\end{array}$ & $\begin{array}{c}\text { PC } \\
n=20\end{array}$ & $\begin{array}{c}\text { Total } \\
n=56\end{array}$ \\
\hline Age, years (Median, (min; max)) & $\begin{array}{c}58 \\
(30 ; 78)\end{array}$ & $\begin{array}{c}63 \\
(52 ; 79)\end{array}$ & $\begin{array}{c}48 \\
(19 ; 83)\end{array}$ & $\begin{array}{c}56 \\
(19 ; 83)\end{array}$ \\
\hline Male & 10 & 4 & 12 & 26 \\
\hline Female & 14 & 8 & 8 & 30 \\
\hline Diabetes mellitus type 2 & 2 & 3 & 2 & 7 \\
\hline Systemic arterial hypertension & 2 & 1 & 2 & 7 \\
\hline Previous abdominal surgical interventions & 24 & 1 & 1 & 26 \\
\hline Duration in hospital, days (Median, (min; max)) & $\begin{array}{c}14 \\
(7 ; 98)\end{array}$ & $\begin{array}{c}18 \\
(12 ; 34)\end{array}$ & $\begin{array}{c}11 \\
(6 ; 33)\end{array}$ & $\begin{array}{c}13 \\
(6 ; 98)\end{array}$ \\
\hline Routine surgical intervention (laparotomy) & 6 & 4 & 20 & 30 \\
\hline Minimally invasive surgical intervention (abscess punction) & 18 & 8 & 0 & 26 \\
\hline \multicolumn{5}{|c|}{ Abscess or peritoneum culture } \\
\hline Gram positive & 3 & 9 & 13 & 25 \\
\hline Enterococcus fecalis & 1 & 3 & 6 & 10 \\
\hline Staphilococcus aureus & - & 4 & 6 & 10 \\
\hline Staphilococcus epidermidis & 1 & 1 & 3 & 5 \\
\hline Gram negative & 19 & 1 & 2 & 22 \\
\hline Escherihia coli & 4 & 3 & 11 & 18 \\
\hline Enterobacter aerogenes & 2 & - & 1 & 3 \\
\hline Enterobacter spp. & 3 & - & - & 3 \\
\hline Pseudomonas aeruginosa & 1 & - & 2 & 3 \\
\hline Edwardsiella tarda & 1 & - & - & 1 \\
\hline Klebsiella spp. & 1 & - & - & 1 \\
\hline Poly & 2 & 2 & 3 & 7 \\
\hline
\end{tabular}

Among 31 healthy individuals of the Control group there were 18 males and 13 females. The median age of them was 57 (minimum, 32; maximum, 77) years ( $\mathrm{KW}$ test $\mathrm{H}=3.0, p=0.2203$ ). There was neither pregnancy nor complaints at the time of blood collection, nor previous surgical interventions, nor medication within the last $72 \mathrm{~h}$, nor chronic diseases.

The Gram-positive infection developed in $25(48.6 \%)$ patients. Gram-negative infection developed in 22 patients (39.2\%). In 2 from 56 patients (3.6\%) bacterial flora was not detected. It is explained by the fact that Gram-negative flora is found significantly more often in patients with postoperative abscesses $(21 / 23)(p=0.0004)$. There was no possibility to isolate flora in one patient with postoperative abscess.

The day before surgical intervention, the total number of leukocytes was statistically significantly lower in patients with postoperative abscesses and primary intra-abdominal abscesses compared with the patients with peritoneal collection, although neutrophils (\%) did not differ.

We found that individuals with different origin of IAI displayed different lengths of hospitalization ( $\mathrm{KW}$ test $\mathrm{H}=6.8, p=0.0320$ ). Kaplan-Meier analysis demonstrated that patients with postoperative abscesses have had more prolonged hospitalization ( $>40$ days), despite the use of minimally invasive technology in 18 (75\%) of them.

In order to gain insight about the inflammatory processes associated with IAI, we evaluated the serum IL-8 $(n=56)$ of these patients before and during 7 days after surgical intervention. The lowest index detected in the Control group (healthy individuals) was $16.67 \mathrm{pg} / \mathrm{mL}$, the highest $-96.3 \mathrm{pg} / \mathrm{mL}$ for IL-8; median serum concentration was $72.07 \mathrm{pg} / \mathrm{mL}$. A difference was found between distributions of serum IL-8 in patients with postoperative abscesses the day before surgical intervention and on the 
2nd-3rd day of the postoperative period, with a significant decrease on 5th-7th days compared with the healthy individuals (Figure 1 ) (KW test $\mathrm{H}=7.1, p=0.0285$ ). There was no significant difference of serum IL-8 distribution in patients with primary intra-abdominal abscesses or peritoneal collection in the perioperative period (Figures 2 and 3) (KW test $\mathrm{H}=0.4, p=0.7969$ and $\mathrm{H}=2.2, p=0.3296$ ).

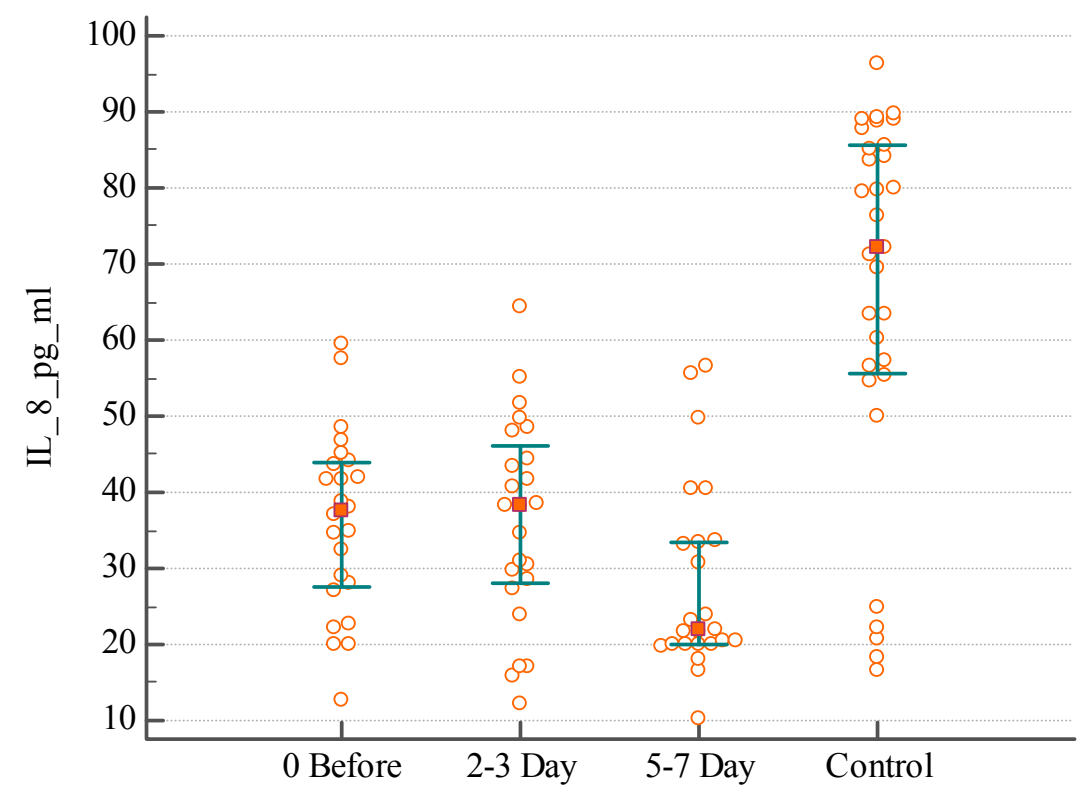

Figure 1. The distribution of serum IL-8 level in patients with postoperative abscesses before, and on the 2 nd-3rd and 5th-7th days after surgical intervention.

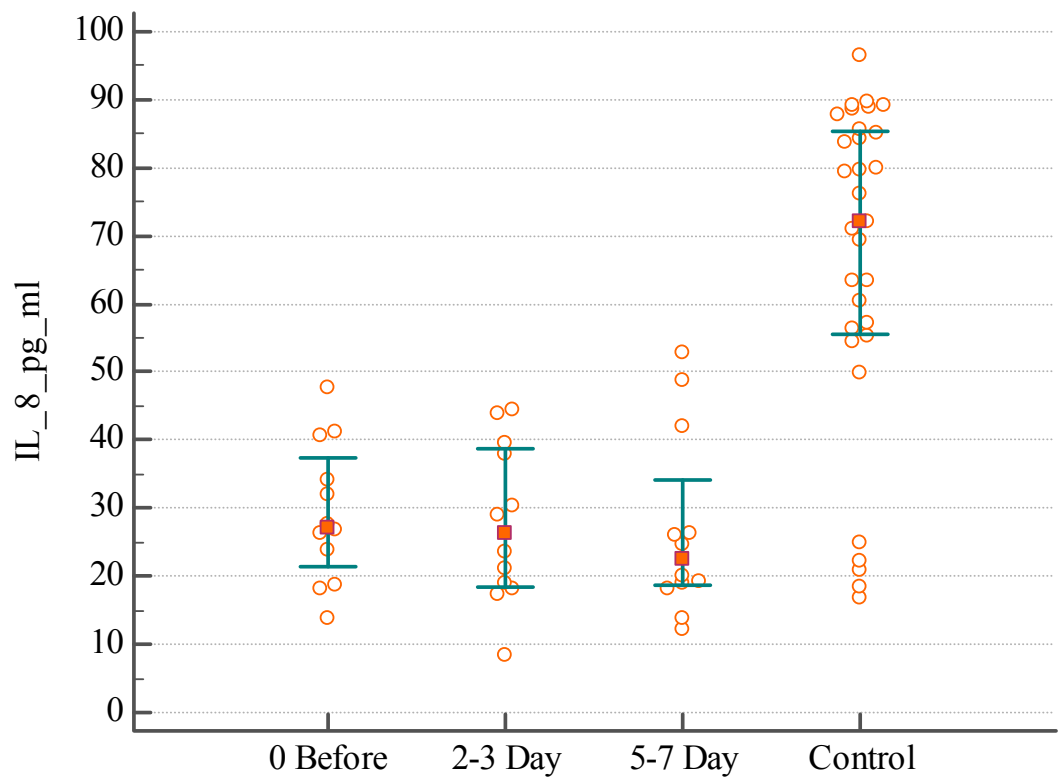

Figure 2. The distribution of serum IL-8 level in patients with primary intra-abdominal abscesses before, and on the 2nd-3rd and 5th-7th days after surgical intervention. 


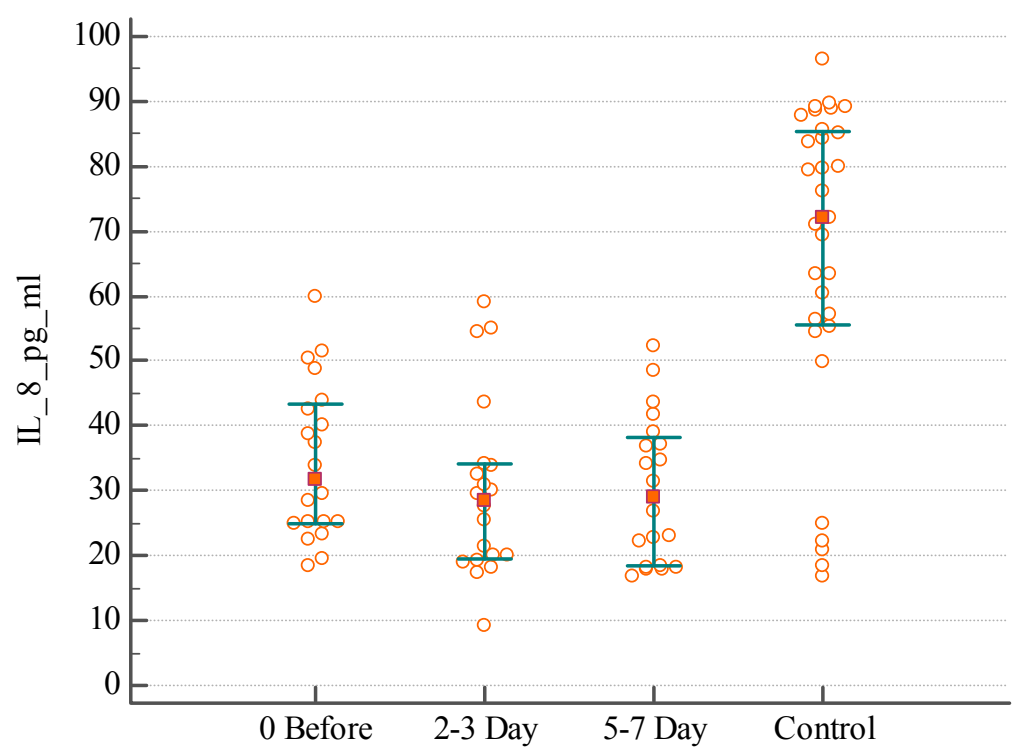

Figure 3. The distribution of serum IL-8 level in patients with diffuse peritoneal collection due to intra-abdominal infections before, and on the 2 nd-3rd and 5 th-7th days after surgical intervention.

As it was expected, the levels of IL-8 in the serum did not differ in individuals with different origin of IAI. For example, the median serum concentration of IL- 8 was $37.68 \mathrm{pg} / \mathrm{mL}$ in patients with postoperative abscesses, $27.21 \mathrm{pg} / \mathrm{mL}$ in patients with primary intra-abdominal abscesses, and 31.62 $\mathrm{pg} / \mathrm{mL}$ in patients with peritoneal collection due to IAI the day before surgical intervention (KW test $\mathrm{H}$ $=2.8, p=0.2381$ ). The median concentration of IL-8 was $38.33 \mathrm{pg} / \mathrm{mL}$ in patients with postoperative abscesses, $26.28 \mathrm{pg} / \mathrm{mL}$ in patients with primary intra-abdominal abscesses, and $28.47 \mathrm{pg} / \mathrm{mL}$ in patients with peritoneal collection on the 2 nd-3rd day after surgical intervention ( $\mathrm{KW}$ test $\mathrm{H}=3.5, p=0.1659$ ). The median concentration of IL- 8 was $21.85 \mathrm{pg} / \mathrm{mL}$ in patients with postoperative abscesses, 22.38 $\mathrm{pg} / \mathrm{mL}$ in patients with primary intra-abdominal abscesses, and $29.11 \mathrm{pg} / \mathrm{mL}$ in patients with peritoneal collection on the 5th-7th day after surgical intervention (KW test $\mathrm{H}=0.5, p=0.7417$ ). The significant difference was found when comparing the concentration IL-8 in serum in patients with IAI and healthy persons (KW test $\mathrm{H}=35.9, p<0.0001$ ).

The distribution of the serum IL-8 level in patients with different origin of IAI before surgical intervention, on the 2nd-3rd and the 5th-7th days of postsurgical intervention see in Supplementary Materials (Figures S1-S3).

The prevalence of a disease may be different in different clinical settings. For our cohort we evaluated sensitivity and specificity of serum IL-8 for IAI in the perioperative period for applies (Table 2).

Table 2. ROC analysis result for serum IL-8 in patients with IAI of different origin.

\begin{tabular}{|c|c|c|c|c|c|c|}
\hline IAI & AUC & $\begin{array}{c}\text { Concentration, } \\
\mathrm{pg} / \mathrm{mL}\end{array}$ & $p$ & $\begin{array}{c}\text { Sensitivity ( } 95 \% \\
\text { Confidential Interval) }\end{array}$ & $\begin{array}{c}\text { Specificity } 95 \% \\
\text { Confidential Interval) }\end{array}$ & $\begin{array}{l}\text { Youden } \\
\text { Index J }\end{array}$ \\
\hline Post-operative abscesses & 0.860 & $\leq 49.71$ & $<0.0001$ & $\begin{array}{c}90.28 \\
(81.0-96.0)\end{array}$ & $\begin{array}{c}83.87 \\
(66.3-94.5)\end{array}$ & 0.7415 \\
\hline $\begin{array}{c}\text { Primary intra-abdominal } \\
\text { abscesses }\end{array}$ & 0.888 & $\leq 48.88$ & $<0.0001$ & $\begin{array}{c}97.22 \\
(85.5-99.9)\end{array}$ & $\begin{array}{c}83.87 \\
(66.3-94.5)\end{array}$ & 0.8109 \\
\hline $\begin{array}{l}\text { Diffuse peritoneal } \\
\text { collection }\end{array}$ & 0.864 & $\leq 54.35$ & $<0.0001$ & $\begin{array}{c}95.00 \\
(86.1-99.0) \\
\end{array}$ & $\begin{array}{c}80.65 \\
(62.5-92.5) \\
\end{array}$ & 0.7565 \\
\hline
\end{tabular}

Of note, the lowest concentration with significant sensitivity and specificity of serum IL-8 was for primary and secondary intra-abdominal abscesses $(p<0.0001)$. 
The curves of ROC analysis for Table 2 see in Supplementary Materials (Figures S4-S7).

We checked our results in two-way ANOVA test where independent factors for IL-8 were time and IAI of different origin (see in Supplementary Materials Figure S8 and Table S1).

\section{Discussion}

Published studies have associated IAI with a prolonged morbidity and significant mortality rate [16-20]. This situation can be associated with some reasons, for example, inadequate empirical antibacterial treatment and poor inflectional control that leads to increasing bacterial resistance [21,22]. Despite increased knowledge about epidemiology and antibiotic therapy, applying minimally invasive technology, our results were similar to those obtained by Vallejo M et al. [23]. Data from Solomkin J.S. et al. show that IAI is still one of the major challenges to the health system [24].

IAI are associated with systemic inflammatory processes. In order to find out how the inflammation was modulated by the infection origin, we measured pro-inflammatory cytokine IL- 8 in the serum of patients with IAI in the perioperative period. We have also investigated the serum level of IL- 8 in 31 healthy individuals. Until now, there is different data regarding the levels of interleukins in intra-abdominal infections. Some publications show high serum levels of IL-8 associated with severe infection and poor outcomes $[25,26]$. Moreover, no correlation was found between the content of cytokines in serum and in the focus of inflammation [2]. Our results with low serum IL-8 level in the perioperative period in patients with IAI of different origin coincide with the data received by Zhengwen Xiao et al. and João Fernando Gonçalves Ferreira et al. which proved that the greatest concentration of IL-8 is contained in the inflammatory focus compared with the serum $[17,18]$.

We showed that the levels of IL-8 in the serum were not different in individuals with different origin of IAI. On the other hand, the lowest concentration of serum IL-8 was in patients with postoperative abscesses at the 5th-7th days after surgical intervention. Currently, postoperative infection is one of the leading causes of sepsis and mortality in patients with IAI. The reason is the nosocomial flora, resistant to antibiotic therapy. The multicenter observational study so-called as WISS (World Society of Emergency Surgery of complicated intra-abdominal infections Score Study), with 4553 patients from 132 hospitals worldwide during 15 October 2014-2015 February 2015, dedicated to validation of patients with complicated IAI, found out that the postoperative infection was in $387(8.5 \%)$ patients and occupied the third position among all source of IAI [27].

We suppose that nosocomial infections exhibit a completely different inflammatory response compared with community-acquired infections, although immunological reactivity should be considered an individual process, which depends on the microbial agent [28].

The next special issue for discussion is Diabetes mellitus, because it is a risk factor for the development of IAI [29]. Chronic hyperglycemia contributes to an increase in the risk of gastrointestinal infections [30]. Concerning cellular innate immunity, most studies show decreased functions of polymorphonuclear cells and monocytes/macrophages. Another mechanism which can lead to the increased prevalence of infections in diabetic patients is an increased adherence of microorganisms to diabetic compared with nondiabetic cells [31]. But the data concerning the level of cytokines are contradictory. So, the study conducted by Cimini F.A. et al. demonstrated that serum IL-8 was increased in diabetic patients [32]. Some investigators claim that the differences in the risk factors for infection between diabetic and nondiabetic patients result either from noncontrolled studies or from biased studies However, most researchers conclude that there is clinical evidence pointing to the higher prevalence of infectious diseases among individuals with Diabetes mellitus [29,33].

Accordingly, Barnett et al. also observed that nosocomial-acquired infections are more severe, requiring longer hospitalization and showing higher death rates in risk-group patients [34].

Pro-inflammatory serum IL-8 was measured only at the peak of disease (peak of inflammation, surgical trauma); they were not continuously monitored at different points of time. Thus, the peak levels of these cytokines were unclear. Measurement of cytokines should be further investigated as a more sensitive determinant of intra-abdominal inflammatory response. 
There were some inherent limitations associated with this study; firstly, sample size. Our model was based on prospective single-center cross-sectional study and was limited by the time and number of patients in the East Ukrainian population. Secondly, there were very few prior researches and gaps in the studies relevant to serum IL-8 in patients with different origin of IAI, which influenced the methodology of our study. Our study was limited by the early perioperative period. There were confounders such as Diabetes mellitus that could influence the serum levels of this pro-inflammatory biomarker [32,33,35]. We were unable to assess whether there was a joint effect of Diabetes mellitus and IAI on cytokine production, which may undermine the strength of the research. As the result, ROC analysis detecting all types of IAI might have misclassified POA as PIAA or PC, which would bias the results of our overall and subgroup analysis toward the null hypothesis. Third, etiological effects of microbial agents on changes in serum IL-8 were not estimated due to diversity and combination. Further investigations of our and different population of pro-inflammatory markers are needed to ascertain their relevance both as early predictor as well as diagnostic cut-offs for IAI. Large-scale studies are needed for the usefulness and effectiveness of IL- 8 as a biomarker, estimated from meta-analyses with validity confirmatory analysis, with people living in other territories.

\section{Conclusions}

The study showed that the level of serum IL-8 in patients with intra-abdominal infections of different origin is lower in comparison with healthy individuals. Its results differ from previous studies that indicated an increase of IL-8. Despite the fact that we did not detect any statistically significant differences in the level of IL-8 in serum in the IAI of different origin in the postoperative period, its lowest index was observed in the patients with postoperative abscesses on the 5th-7th days after surgical intervention compared with the Control group. The levels of serum IL- $8 \leq 49.71 \mathrm{pg} / \mathrm{mL}$ and $\leq 48.88 \mathrm{pg} / \mathrm{mL}$ may serve as diagnostic markers for primary and postoperative abscesses with significant sensitivity and specificity. The relationship between the cytokine response and the specific nosocomial bacterial agent, the mechanisms of localization, and generalization of the infection process should be further studied. High-quality clinical trials are needed to better comprehend the role of inflammatory mediators in IAI with different origin.

Supplementary Materials: The following are available online at http://www.mdpi.com/2076-3271/7/9/94/s1, Figure S1 Distribution of the serum IL-8 level in patients with different origin of IAI before surgical intervention; Figure S2 Distribution of the serum IL-8 level in patients with different origin of IAI on the 2nd-3rd days of postsurgical intervention; Figure S3 Distribution of the serum IL-8 level in patients with different origin of IAI on the 5th-7th days of postsurgical intervention; Figure S4. Results of ROC analysis for Postoperative Abscesses; Figure S5 Results of ROC analysis for Postoperative Abscesses; Figure S6 Results of ROC analysis for Primary Intra-Abdominal Abscesses; Figure S7 Results of ROC analysis for Peritoneal collection; Figure S8. Result of two-way ANOVA test; Table S1 Two-way ANOVA: for serum IL-8 in patients with different origin of IAI.

Author Contributions: V.B. conceived of the presented idea and conceptualization; performed supervision, and management, and coordination responsibility for the research activity planning and execution; V.B. and Y.G. designed the methodology of the study; A.R. developed software; data validation, and formal analysis, provision of study materials and laboratory samples, prepared of original draft; A.R. and Y.G. performed of the investigational process and data curation; V.B. and A.R. prepared revision and visualization. All authors discussed the results and contributed to the final manuscript.

Funding: This research received no external funding.

Acknowledgments: Authors thank the Central Research Laboratory team of Kharkiv National Medical University for technical support.

Conflicts of Interest: The authors declare no conflict of interest.

\section{References}

1. Karantonis, F.F.; Nikiteas, N.; Perrea, D.; Vlachou, A.; Giamarellos-Bourboulis, E.J.; Tsigris, C.; Kostakis, A. Evaluation of the effects of laparotomy and laparoscopy on the immune system in intra-abdominal sepsis-A review. J. Investig. Surg. 2008, 21, 330-339. [CrossRef] [PubMed] 
2. Riché, F.; Gayat, E.; Collet, C.; Matéo, J.; Laisné, M.; Launay, J.; Valleur, P.; Payen, D.; Cholley, B.P. Local and systemic innate immune response to secondary human peritonitis. Crit. Care 2013, 17, R201. [CrossRef] [PubMed]

3. Medzhitov, R. Pattern recognition theory and the launch of modern innate immunity. J. Immunol. 2013, 191, 4473. [CrossRef] [PubMed]

4. Bickel, M. The role of interleukin-8 in inflammation and mechanisms of regulation. J. Periodontol. 1993, 64 (Suppl. S5), 456-460. [PubMed]

5. Lin, E.; Calvano, S.E.; Stephen, F. Lowry, Flushing, and New Brunswick. Inflammatory cytokines and cell response in surgery. Surgery 2000, 127, 117-126. [CrossRef] [PubMed]

6. Loftus, T.J.; Mira, J.C.; Stortz, J.A.; Ozrazgat-Baslanti, T.; Ghita, G.L.; Wang, Z.; Brumback, B.A.; Ungaro, R.F.; Bihorac, A.; Leeuwenburgh, C.; et al. Persistent Inflammation and Anemia among Critically Ill Septic Patients. J. Trauma Acute Care Surg. 2018, 86, 260-267. [CrossRef] [PubMed]

7. Sjögren, F.; Anderson, C. Sterile trauma to normal human dermis invariably induces IL1 beta, IL6 and IL8 in an innate response to "danger". Acta Derm. Venereol. 2009, 89, 459-465. [CrossRef] [PubMed]

8. Norton, J.A.; Bollinger, R.R.; Chang, A.E.; Lowry, S.F.; Mulvihill, S.J. Surgery: Basic Science and Clinical Evidence; Springer: New York, NY, USA, 2008.

9. Xiao, P.; Long, X.; Zhang, L.; Ye, Y.; Guo, J.; Liu, P.; Zhang, R.; Ning, J.; Yu, W.; Wei, F.; et al. Neurotensin/IL-8 pathway orchestrates local inflammatory response and tumor invasion by inducing M2 polarization of Tumor-Associated macrophages and epithelial-mesenchymal transition of hepatocellular carcinoma cells. Oncoimmunology 2018, 7, e1440166. [CrossRef]

10. Pease, J.E.; Sabroe, I. The role of interleukin- 8 and its receptors in inflammatory lung disease: Implications for therapy. Am. J. Respir. Med. 2002, 1, 19-25. [CrossRef]

11. Zhao, F.X.; Liu, G.H.; Zhang, J. Value of IL-6 and IL-8 in the diagnosis of neonatal sepsis. Chin. J. Contemp. Pediatr. 2015, 17, 1311-1315.

12. Ku, Y.; Hong, S.M.; Fujikura, K.; Kim, S.J.; Akita, M.; Abe-Suzuki, S.; Shiomi, H.; Masuda, A.; Itoh, T.; Azuma, T.; et al. IL-8 Expression in Granulocytic Epithelial Lesions of Idiopathic Duct-centric Pancreatitis (Type 2 Autoimmune Pancreatitis). Am. J. Surg. Pathol. 2017, 41, 1129-1138. [CrossRef] [PubMed]

13. Namba, S.; Nakano, R.; Kitanaka, T.; Kitanaka, N.; Nakayama, T.; Sugiya, H. ERK2 and JNK1 contribute to TNF- $\alpha$-induced IL-8 expression in synovial fibroblasts. PLoS ONE 2017, 12, e0182923. [CrossRef] [PubMed]

14. Shahzad, A.; Knapp, M.; Lang, I.; Köhler, G. Interleukin 8 (IL-8)—A universal biomarker? Int. Arch. Med. 2010, 3, 11. [CrossRef] [PubMed]

15. Hikmet, K. Determination of diagnostic and prognostic values of urinary interleukin-8, tumor necrosis factor-, and leukocyte arylsulfatase-A activity in patients with bladder cancer. Clin. Biochem. 2004, 37, 673-678. [CrossRef]

16. Sapin, F.; Biston, P.; Piagnerelli, M. Predictive value of C-reactive protein in critically ill patients after abdominal surgery. Clinics (Sao Paulo) 2017, 72, 23-29. [CrossRef]

17. Xiao, Z.; Wilson, C.; Robertson, H.L.; Roberts, D.J.; Ball, C.G.; Jenne, C.N.; Andrew, W. Kirkpatrick Inflammatory mediators in intra-abdominal sepsis or injury-A scoping review. Crit. Care 2015, 19, 373. [CrossRef]

18. Ferreira, J.F.G.; Rezende-Neto, J.B.; Pinto-Silva, R.A.; de Souza, J.G.; Farias, L.D.; de Carvalho, M.A.R.; Santiago, H.; Serufo, J.C.; Santos, S.G.D. Microbiota Evaluation and Extracellular Cytokine Profile in Patients Affected with Intraabdominal Infection. Br. J. Med. Med. Res. 2016, 15, 1-14. [CrossRef]

19. Sartelli, M.; Catena, F.; Abu-Zidan, F.M. Management of intra-abdominal infections: Recommendations by the WSES 2016 consensus conference. World J. Emerg. Surg. 2017, 12, 22. [CrossRef]

20. Tang, H.; Lu, W.; Yang, Z.; Jiang, K.; D, M.; Chen, Y.; Lu, S.; Dong, J. Risk factors and long-term outcome for postoperative intra-abdominal infection after hepatectomy for hepatocellular carcinoma. Medicine (Baltimore) 2017, 96, e6795. [CrossRef]

21. Heizmann, W.R.; Dupont, H.; Montravers, P.; Guirao, X.; Eckmann, C.; Bassetti, M.; García, M.S.; Capparella, M.R.; Simoneau, D.; Bodmann, K.F. Resistance mechanisms and epidemiology of multiresistant pathogens in Europe and efficacy of tigecycline in observational studies. J. Antimicrob. Chemother. 2013, 68 (Suppl. S2), 45-55. [CrossRef] 
22. Miller, B.; Popejoy, M.W.; Hershberger, E.; Steenbergen, J.N.; Alverdy, J. Characteristics and Outcomes of Complicated Intra-abdominal Infections Involving Pseudomonas aeruginosa from a Randomized, Double-Blind, Phase 3 Ceftolozane-Tazobactam Study. Antimicrob. Agents Chemother. 2016, 60, 4387-4390. [CrossRef] [PubMed]

23. Vallejo, M.; Cuesta, D.P.; Flórez, L.E.; Correa, A.; Llanos, C.E.; Isaza, B.; Vanegas, S.; Osorio, J.; Casanova, L.; Villegas, M.V. Clinical and microbiological characteristics of complicated intra-abdominal infection in Colombia: A multicenter study. Rev. Chil. Infectol. 2016, 33, 261-267. [CrossRef] [PubMed]

24. Solomkin, J.S.; Meakins, J.L., Jr.; Allo, M.D.; Dellinger, E.P.; Simmons, R.L. Antibiotic trials in intra-abdominal infections. A critical evaluation of study design and outcome reporting. Ann. Surg. 1984, 200, $29-39$. [CrossRef] [PubMed]

25. Easton, R.; Balogh, Z.J. Peri-operative changes in serum immune markers after trauma: a systematic review. Injury 2014, 45, 934-941. [CrossRef] [PubMed]

26. Kraft, R.; Herndon, D.N.; Finnerty, C.C.; Cox, R.A.; Song, J.; Jeschke, M.G. Predictive Value of IL-8 for Sepsis and Severe Infections After Burn Injury: A Clinical Study. Shock 2015, 43, 222-227. [CrossRef] [PubMed]

27. Sartelli, M.; Abu-Zidan, F.M.; Catena, F.; Griffiths, E.A.; di Saverio, S.; Coimbra, R.; Ordoñez, C.A.; Leppaniemi, A.; Gustavo, P.; Fraga, F.C.; et al. Global validation of the WSES Sepsis Severity Score for patients with complicated intra-abdominal infections: A prospective multicentre study (WISS Study). World J. Emerg. Surg. 2015, 10, 61. [CrossRef] [PubMed]

28. Sinapidis, D.; Kosmas, V.; Vittoros, V.; Koutelidakis, I.M.; Pantazi, A.; Stefos, A.; Katsaros, K.E.; Akinosoglou, K.; Bristianou, M.; Toutouzas, K.; et al. Progression into sepsis: An individualized process varying by the interaction of comorbidities with the underlying infection. BMC Infect. Dis. 2018, 18, 242. [CrossRef] [PubMed]

29. Mazuski, J.E.; Tessier, J.M.; May, A.K.; Sawyer, R.G.; Nadler, E.P.; Rosengart, M.R.; Chang, P.K.; O’Neill, P.J.; Mollen, K.P.; Huston, J.M.; et al. The Surgical Infection Society Revised Guidelines on the Management of Intra-Abdominal Infection. Surg. Infect. 2017, 18, 1-76. [CrossRef]

30. Casqueiro, J.; Casqueiro, J.; Alves, C. Infections in patients with diabetes mellitus: A review of pathogenesis. Indian J. Endocrinol. Metab. 2012, 16 (Suppl. S1), S27-S36. [CrossRef]

31. Geerlings, S.E.; Hoepelman, A.I.M. Immune dysfunction in patients with diabetes mellitus (DM). FEMS Immunol. Med. Microbiol. 1999, 26, 259-265. [CrossRef]

32. Cimini, F.A.; Barchetta, I.; Porzia, A.; Mainiero, F.; Costantino, C.; Bertoccini, L.; Ceccarelli, V.; Morini, S.; Baroni, M.G.; Lenzi, A.; et al. Circulating IL-8 levels are increased in patients with type 2 diabetes and associated with worse inflammatory and cardiometabolic profile. Acta Diabetol. 2017, 54, 961-967. [CrossRef] [PubMed]

33. Muller, L.M.; Gorter, K.J.; Hak, E.; Goudzwaard, W.L.; Schellevis, F.G.; Hoepelman, A.I.; Rutten, G.E.H.M. Increased risk of common infections in patients with type 1 and type 2 diabetes mellitus. Clin. Infect. Dis. 2005, 41, 281-288. [CrossRef] [PubMed]

34. Barnett, A.G.; Page, K.; Campbell, M.; Martin, E.; Rashleigh-Rolls, R.; Halton, K.; Paterson, D.L.; Hall, L.; Jimmieson, N.; White, K.; et al. The increased risks of death and extra lengths of hospital and ICU stay from hospital-acquired bloodstream infections: A case-control study. BMJ Open 2013, 3, e003587. [CrossRef] [PubMed]

35. Delamaire, M.; Maugendre, D.; Moreno, M.; Le Goff, M.-C.; Allannic, H.; Genetet, B. Impaired leucocyte functions in diabetic patients. Diabet. Med. 1997, 14, 29-34. [CrossRef]

(C) 2019 by the authors. Licensee MDPI, Basel, Switzerland. This article is an open access article distributed under the terms and conditions of the Creative Commons Attribution (CC BY) license (http://creativecommons.org/licenses/by/4.0/). 